Educational Research for Social Change (ERSC)

Volume 10 No. 2 September 2021

pp. 88-104

ersc.nmmu.ac.za

ISSN: 2221-4070

\title{
A Critical Approach to University-Community Partnerships: Reflecting on the Diverse Realities ${ }^{1}$
}

\author{
Heloise Sathorar \\ ORCID No: 0000-0002-4947-0885 \\ Nelson Mandela University \\ Heloise.Sathorar@mandela.ac.za
}

\section{Deidre Geduld}

ORCID No: 0000-0001-6175-0508

Nelson Mandela University

Deidre.Geduld@mandela.ac.za

\begin{abstract}
Postapartheid South Africa has seen a greater focus on community engagement by universities, and its inclusion as one of the core focus areas of higher education in addition to teaching and research. This focus on engagement with the community was ignited by a requirement to enhance the university's social responsibility through establishing partnerships with the communities it serves. Higher education institutions have traditionally positioned themselves in engagement projects as the singular organisation that has knowledge to offer when compared to what the community can offer. In this paper, we propose a critical engagement process to enhance collaboration in engagement projects. Our qualitative study resides in a critical theory paradigm, and we used drawings as well as narrative free writing to reflect and explore our perceptions regarding community engagement. We used the collaborative self-study methodology because it provides opportunities for critical and self-critical reflection that could lead us to discovering valuable insights, as well as provide suggestions on how to enhance university community partnerships. Our findings suggest that, despite legislation and efforts to enhance university community engagement, this remains a contested space where power relations, inequality, and claims to knowledge ownership continue to pose challenges.
\end{abstract}

Keywords: collaboration, collaborative self-study, critical community engagement, critical pedagogy

Copyright: @ 2021 Sathorar and Geduld

This is an open access article distributed under the terms of the Creative Commons Attribution NonCommercial License, which permits unrestricted non-commercial use, distribution, and reproduction in any medium, provided the original author and source are credited.

\footnotetext{
${ }^{1}$ Ethical clearance number: NWU-00782-18-S2
} 
Please reference as: Sathorar, H. and Geduld, D. (2021). A Critical Approach to UniversityCommunity Partnerships: Reflecting on the Diverse Realities. Educational Research for Social Change, 10 (2), 88-104. http://dx.doi.org/10.17159/2221-4070/2021/v10i2a6

\section{Introduction}

Ernest Boyer (1990) introduced the notion of an organisation that is intrinsically linked to the public in which it resides, referring to it as an engaged institution; he postulated that universities were not merely located in a community but were active members of the community. Thus, the university has an integral role to play in the welfare and development of the community. The idea that universities can contribute to, and learn from, the communities around them is increasingly gaining attention (Bhagwan, 2017). Community engagement has emerged as a top priority at universities - to collaborate and facilitate the mutually beneficial exchange of knowledge and resources for both universities and communities (Jadhav \& Suhalka, 2016). This supports the task given to higher education institutions (HEIs) by the national government to address societal challenges in a way that will contribute to societal transformation (Department of Education, 1997).

Despite forefronting community engagement, and legislation encouraging the establishment of collaborative and mutually beneficial university-community partnerships, this has remained a contested space. University-community engagement in South Africa continues to be characterised by universities engaging with communities to extract data to further their own research agenda and, in the process, not acknowledging community needs and also not contributing to sustainable benefits for the community. Community partners claim that they have no say in what issues are researched and complain about being exploited through the power imbalance in the partnership (Cooper \& Orrell, 2016). Thus, universities have to ask why and how do they engage with their communities, as well as whether their engagement would contribute to social transformation and the development of a socially just society. Universities have to acknowledge that their structure and culture can simultaneously serve as opportunities and also create barriers to community engagement that would contribute to social transformation. In this paper, we highlight the disjuncture that exists between the objectives of the university and community regarding community engagement. We propose a critical approach to community engagement by drawing on the three educational aims of critical pedagogyhumanisation, conscientisation, and problem posing-in order to enhance the collaboration and collective outcomes of community engagement.

\section{Background and Problem Statement}

HEls in South Africa (SA) have not brought about the desired outcome of improving their engagement agenda with their communities (Wood, 2016). In this paper, we grapple with the question: "For whom and how is community engagement done?" We operate under the assumption that the university, as a public institution with a mandate for the public good, has the power to facilitate mutual growth with communities in relation to who they are, who they are in relation to others, and who they are in relation to the larger society (Giroux, 2006). Currently, universities in SA follow community engagement practices that support reproduction of the status quo, which is one that supports the neoliberal agenda by ignoring the political nature of community engagement, amongst other things (Bhagwan, 2017). This has pushed us to ask: "How do we get university academics to embrace engagement critically, and what can be done to help them to see themselves as public intellectuals working towards a common good?" Reflecting on our work in university-community partnership projects, we investigate how we can bridge the gap between how university-community engagement has been done traditionally, and the potential and possibilities of critical and participatory universitycommunity partnerships. 
The aim of critical university engagement is to bring about social change; however, not enough attention is given to the fact that the university serves diverse personal and societal purposes and that these purposes are deeply contested. Fataar and Subreenduth (2016) were of the opinion that public education policy in HEls in SA is currently dominated by an overemphasis on education throughput and educational productivity where university academics are increasingly asked to reproduce knowledge structures at the expense of committing epistemicide (De Sousa Santos, 2014). In other words, universities ignore the knowledge and value systems of the communities they serve and impose their own knowledge and value systems on these communities. In this paper, we reflect on the disjuncture that exists between the objectives of the university and community regarding community engagement, and endeavour to provide suggestions to enhance the relationship between universities and communities in engagement projects.

\section{Importance of University-Community Engagement}

In this section, we unpack the concept of university-community engagement and what it entails, and we also look at the challenges experienced in these partnerships. We conclude by providing suggestions on how university-community partnerships can be enhanced.

\section{Definition and Purpose of University-Community Engagement}

The discourse on community engagement has remained prominent and not without challenges in the HEl environment over the last couple of decades (Mtawa et al., 2016). Despite government's encouragement and the general support for universities to become involved in community engagement, there is no uniform understanding of what this entails (Kruss, 2012). There is no commonly accepted and agreed upon definition for community engagement. Cooper and Orrell (2016) explicated that university-community engagement involves a relationship between universities and the community that will support research and facilitate learning through teaching practice, community service, and other public engagement. Even this broad description of what university-community engagement entails seems to be problematic because it forefronts the objectives of the university rather than common objectives identified through collaboration with the community. This reinforces the hegemonic notion that the university is the knower and the knowledge creator.

There has been a transition from using a one-way model to a two-way model for community engagement. The one-way model emphasised delivery of knowledge and service to the public whereas in the two-way model, universities embrace a collaborative approach to knowledge exchange with the communities it serves and thereby contribute to the development of mutually beneficial partnerships (Mtawa et al., 2016). This understanding of the two-way model has initiated various definitions and theoretical conceptualisations of what university-community engagement entails. Cooper and Orrell highlighted that the Carnegie Foundation for the Advancement of Teaching's definition of community engagement refers to a partnership between university and communities:

[It] is the partnership of college and university knowledge and resources with those of the public and private sectors to enrich scholarship, research, and creative activity; enhance curriculum, teaching and learning; prepare educated, engaged citizens; strengthen democratic values and civic responsibility; address critical societal issues; and contribute to the public good. (as quoted in Cooper \& Orrell, 2006, p. 109)

Holland and Ramley also drew on the Carnegie Foundation's definition but added the notion of reciprocity: 
Community engagement describes the collaboration between institutions of higher education and their larger communities for mutually beneficial exchange of knowledge and resources in a context of partnership and reciprocity. (2008, p. 35)

Similarly, Wood (2016) emphasised collaboration with community partners to enhance the development of sustainable and ethical community engagement. This raises awareness of the potential and possibility for change amongst participants. We support the definition suggested by the Centre for Higher Education Transformation, which defined community engagement as:

\begin{abstract}
a systematic relationship between Higher Education [Institutions] and [their] environment [communities] that is characterized by mutually beneficial interaction in the sense that it enriches learning, teaching and research and simultaneously addresses societal problems, issues and challenges. (2003, p. 4)
\end{abstract}

This definition advocates for community engagement to be collaborative and to focus on mutual objectives through co-inquiry and co-learning; contributing to research but simultaneously addressing real community problems (Mtawa et al., 2016; Zuber-Skerritt et al., 2020).

\title{
Challenges Experienced in University-Community Partnerships
}

Despite universities explicitly forefronting community engagement in their policy documents and referring to it in their social responsibility profile development, there are several hurdles to the implementation of these plans. Mtawa et al. (2016) explicated that institutional culture can serve as a barrier to community engagement. In most universities, there is not a dedicated department that promotes community engagement, and academics are left to seek their own link between their teaching, research, and engagement projects. At Nelson Mandela University, this challenge was acknowledged by the vice-chancellor, Professor Sibongile Muthwa, in her inaugural address where she proposed the establishment of a Hub of Convergence to create a space for academics to launch engagement projects (Muthwa, 2019). The commitment to create an institutional culture that would support community engagement was strengthened by appointing a deputy vice-chancellor whose portfolio specifically included community engagement.

However, the above practices are not commonly followed and community engagement is not prioritised but, rather, done as an add-on or afterthought (McNair \& Ramaley, 2018). This results in limited and very superficial interactions between academics and communities. Furthermore, it leads to limited incorporation of community engagement activities into the teaching and res earch projects of the university. The differences in resource availability, as well as the circumstantial realities between the university and its community partners, pose a further barrier to engagement projects (Bhagwan, 2017; Smith et al., 2017). Inadequate resources and lack of infrastructure in communities encourages universities to bring communities to well-equipped university campuses for meetings that are distant from the contextual realities that the communities experience (Cooper \& Orrell, 2016). Thus, community members claim that universities start engagement partnerships with pre-determined objectives to satisfy specific teaching and research goals that are far removed from the societal challenges the community is facing (Strier, 2010). The lack of resources, including funds and infrastructure, also contributes to the power imbalance in university-community partnerships.

Thus, communities doubt the authenticity of universities' commitment to community engagement because they believe the university is only interested in social matters to facilitate student learning and research. Community scepticism is increased when university engagement projects exclude ethical procedures, agreed upon guiding principles, and empowering involvement in projects that would result in mutual benefits (Bhagwan, 2017; Cooper \& Orrell, 2016; Strier, 2010). Communities claim that 
engagement project outcomes seem to be in favour of universities and not the community. It seems as if academic institutions prioritise their goals in engagement projects in an uncritical way. Community partners further claim that even when they raise concerns, the concerns are not addressed (Smith et al., 2017). Finally, communities mention that their experience and indigenous knowledge are not acknowledged (Strier, 2010) and that the outcomes of these partnerships are often not sustainable (Bhagwan, 2017).

\section{How to Enhance University and Community Engagement?}

Cooper et al. (2010) argued that effective university-community partnerships must seek to ensure lasting mutual benefit for all stakeholders. Similarly, Shannon and Wang (2010) advocated for university-community partnerships to be established to address mutual issues, which do not just focus on research issues identified by the university. They further advocated for university-community partnerships to be prioritised and not seen as an add-on to academic activities-and also, for stakeholders to be convened around a common issue (Shannon \& Wang, 2010). Community engagement would benefit from the provision of a neutral space and leadership that embraces collaboration among diverse participants to identify common goals that would encourage action and bring about social transformation (Edmondson \& Zimpher, 2014).

Bhagwan (2017) supported the above views and described community engagement as mutually beneficial partnerships between communities and the university. This definition emphasises the notions of mutuality and reciprocity and supports co-designing solutions for common issues. Codesigning, which can also be called participatory design solutions, assists in making the community feel less exploited and reduces their scepticism regarding community projects. Understanding the community needs, discussing, co-designing, and developing an implementable solution would no longer make the community feel as if the university were imposing a solution on them (Bhagwan, 2017; Edmondson \& Zimpher, 2014). It allows the community to develop a voice, and it helps with the reconfiguration of the power relations in the partnership.

In this paper, we reflect on the disjuncture that exists between the objectives of the university and community regarding community engagement. Furthermore, we advocate for university-community partnerships and engagement projects that go beyond opportune coalitions and aim for mutual benefit and reciprocity for all stakeholders. This would require the university and the community to fully understand each other's goals and, in the process, align their own goals with those of their partners (Cooper \& Orrell, 2016). Mutual benefit will only be obtained if universities and their community partners do not only focus on their own goals but, rather, work towards the achievement of common goals that would contribute to the good of all and, in particular, to the good of their partners in the project. This type of reciprocity in university-community engagements would be achieved through mutual respect between partners that understand each other's agendas and work towards obtaining common goals.

Furthermore, these partnerships are characterised by trust amongst partners, honesty, sincerity, and a dedication to resolve challenges that might arise in the partnership (Smith et al., 2017). They further suggested that fairness, justice, honesty, and a commitment to shared authority and respect for one another's goals be used as guiding principles for reciprocal partnerships (Smith et al., 2017). Such partnerships honour and respect the goals of both partners and encourage the use of the university's resources to work towards achieving common goals that will benefit all (Edmondson \& Zimpher, 2014; McNair \& Ramaley, 2018; Smith et al., 2017). 


\section{Theoretical Framework}

Based on the need for university-community partnerships in engagement projects to be mutually beneficial and reciprocal, we have framed the research that was done for this paper in a critical paradigm, and have drawn on the three educational aims of critical pedagogy, namely, humanisation, conscientisation, and problem posing.

Humanisation is closely linked to true dialogue and Freire (1970) highlighted that changing the world into a humanised place is only feasible through true dialogue occurring under the following conditions: profound love for the world and human beings, humility towards each other and the world, faith in humanity and in its power to create and re-create, mutual trust between dialoguers, hope for a better future, and the ability to think critically. Moreover, Freire (1970, p. 17) postulated that "only dialogue, which requires critical thinking, is capable of generating critical action." Without dialogue, there is no communication and, without communication, there can be no true social transformation (Sathorar, 2018). In this paper, we advocate for true dialogue during university-community engagement projects.

Community engagement is essentially a learning process and, from a critical perspective, conscientisation is one of the most important characteristics of authentic learning (Nouri \& Sajjadi, 2014). Freire (1970, p. 17) defined conscientisation as "to learn to perceive social, political and economic contradictions and to take action against the oppressive elements of reality." The process of conscientisation occurs when the university and its community partners "know that they know" - and act upon this knowing (Nouri \& Sajjadi, 2014, p. 80). Thus, conscientisation involves a type of knowing that includes understanding and also the ability to act on this knowing in such a way as to bring about change (Sathorar, 2018). Shor (1992) identified four qualities of critical consciousness that enhance problem solving: power awareness, critical literacy, permanent de-socialisation, and self-education. He elucidated that power awareness is constructed on the assumption that social structures are developed by human effort and it can thus also be changed by human effort (Shor, 1992). Critical literacy enhances critical consciousness and involves the analysis of readings and engaging in deep reflection to determine and understand the origins of social issues (Darder, 2017). The third quality of critical consciousness is permanent de-socialisation; it involves questioning dominance and discrimination in the existing state of affairs, as well as investigating socialised values in human consciousness that hamper democratic change, both in the individual and in the larger society; this quality promotes a passion for social justice (Shor, 1992). Shor's (1992) final quality is self-education, which refers to having the knowledge to participate and learn from others in transformative projects. In this paper, we argue for conscientisation in university-community engagements and propose the application of the above qualities during engagement projects.

Freirean critical pedagogy focuses on tapping into silenced voices and determining why these voices have been suppressed (Sathorar, 2018). Freire (1970, p. 21) proposed a problem-posing education that encourages the questioning of all knowledge as opposed to accepting it as "central bank wisdom." Problem-posing can be seen as a pedagogy of questioning (Nouri \& Sajjadi, 2014), and it encourages the university and the community to analyse and interrogate their own knowledge and experiences in relation to those of others to reveal larger public issues and processes of domination and liberation (Darder, 2017). Shudak (2014) emphasised that the aim of problem posing is not to generate a solution but, rather, to collectively explore the complexity and inter-relatedness of individual, organisational, and social issues to engage with and learn about a problem and its context, and to identify ways to take collective actions that constructively respond to the problem. We advocate for problem-posing strategies to be applied in university-community engagement projects. 


\section{Research Design and Methodology}

This qualitative study draws on the experiences of two critical researchers to explore their understanding of university-community partnerships. A qualitative research approach was followed because it focuses on phenomena that occur in the real world. The phenomenon under investigation in this research is how to enhance community engagement partnerships between the university and the communities it serves. Hammersley (2013) described qualitative research as a form of scientific inquiry that can be used to understand complex social processes such as the focus area of the current study. Furthermore, we refer to Leedy and Omrod's (2018) description of the purpose of a qualitative approach as justification for the use in this study. A qualitative approach allows for the description, interpretation, verification, and evaluation of data that will assist to reveal the nature of a certain situation as well as allow the researchers to gain insight about the particular phenomena (Leedy \& Omrod, 2018).

The research that informs this paper resides in a critical theory paradigm. Critical refers to one's ability to think deeply about an issue and to ask investigative questions. Criticality is concerned with conceptualisation of the theory that informs the taken-for-granted knowledge and methods used; it will expose existing assumptions and understandings that maintain unequal power relations and unjust social position in phenomena (Maxwell, 2012). Critical theory is relevant for this study because it allows the researcher to analyse a social phenomenon and to identify what is wrong with the situation as well as who would be able to rectify it to bring about social transformation (Flick, 2014). This theory supports social justice and seeks to bring about a society that is based on fairness and equal rights for all people. It identifies the untruths and incorrect assumptions, as well as dishonest behaviour, that brought a certain individual or group to power or powerlessness and interrogates the rightfulness and validity of this power relation (Maxwell, 2012). Furthermore, Flick (2014) explicated that critical theory investigates issues of discrimination and oppression, and promotes freedom of expression and equality for all. Thus, the purpose of a critical theory paradigm in research is practical and focuses on bringing about a more free, democratic society in which equality for all is secured. A critical theory is not just focussed on enhancing existing knowledge or beliefs but also strives towards making a meaningful difference in the actual lives and real circumstances of a community. This confirms the relevance of the paradigm for this research, which is based on how to enhance university-community engagement.

Collaborative self-study was employed as a research design to allow us to reflect on our personal experience and practice of community engagement projects. Stenhouse (1975), in his seminal work on collaborative self-study, proposed a systematic and methodical approach to research that would allow researchers to enhance their practices. He mentioned that an imperative characteristic of a researcher is the ability to focus on self-enhancement by engaging in systematic self-study and then comparing what they discover with the work of other researchers. Self-study is a research strategy that allows researchers to investigate their own practice and the role they play in it (Brookfield, 2017). Furthermore, it allows them to identify the underlying motivations, beliefs, and values that inform their practices. This process involves the participation of critical friends (Vanassche \& Kelchtermans, 2016) comparing practice to theory to gain a better understanding of practice, and meticulous analysis of one's own practice (Bruce \& Chiu, 2015). Using a self-study approach will not only allow us to reflect and improve our own practice but also allow us to contribute to the debate regarding universitycommunity engagement and, subsequently, to the knowledge available on community engagement practices.

We used self-study as an empowering method to examine and learn about our own understanding and experiences of community engagement. It necessitates the building of a relationship between the individual and collective cognition of researchers, and employs dialogue to establish a collaborative learning community (Bruce \& Chiu, 2015). We chose to engage in collaborative self-study because it 
allowed us to collectively reflect and critically analyse our own practice regarding community engagement through systematic inquiry; and because it allowed us to contribute to the broader knowledge base regarding community engagement projects. Furthermore, collective collaboration enhances one's view of an issue because it provides you with alternative views regarding it. Comparing different views helps you to confirm and justify the quality and validity of each of the different views (Bruce \& Chiu, 2015).

In this study, we engaged in collaborative self-study by using drawings and narrative free writing to tap into our own experiences of community engagement. We explained our drawings and analysed our narratives collaboratively to enhance our understanding of what community engagement entails and how it should be done. Rose (2016) highlighted that drawings are available to all because they are inherently human, social, and communicative and thus there is no cultural group that does not have a relationship with them. The drawings were used in conjunction with narratives as we engaged in free writing (Gilbertson, 2013) as a data-gathering tool. Furthermore, we are reminded that drawings can express that which is not easily put into words: the ineffable, the elusive, the not-yet-thought-through, and the subconscious (Gilbertson, 2013). Drawings can give expression to the lived experiences of those who produce them.

Rose (2016) emphasised that it is up to the creator of the drawing to decide when, how, and with whom they will share the story behind the drawing. We reflected on our experience in universitycommunity partnerships by utilising the prompt: "How do we experience university-community partnerships?" Our drawings communicated a range of perspectives regarding understandings of how we experience university-community engagement, and exposed significant challenges regarding mutual benefits, shared goals, and power relations. The drawings also reflected the tensions we experienced as we were reminded of what we went through when we were community members engaged in university research and we compared that with what we are currently doing as university researchers. This tension was reflected in all the drawings that were made and there were no specific drawings that only depicted our experience as community members.

In our contact session, we used coloured pencils and A4 print pages, and each participant had 120 minutes to respond to the prompt through drawings. Our rough drawings were later enhanced by a computer application to improve the colour and dimension. However, none of the original images was changed by this process. These drawings were supported by narrative free writing we did to explain them. According to Elbow (1973), free writing is a process of learning and growing during which thinking is stimulated, enhanced, and expressed. Furthermore, Elbow $(1998$, p. 5) held the opinion that the spontaneous nature of free writing eases the mental burden of trying to "think of words and also worry at the same time whether they are the right words." The prompt that informed our free writing was: "Explain your drawings." We allocated 10 uninterrupted minutes to describe each of our drawings. We used narrative free writing because it allowed us to express ourselves without any reservation regarding the flow and structure of our words, and to tap into deep feelings about what the drawings meant.

Afterwards, we had to highlight the main points of our narrative free writing and shared these with each other. We allowed for clarifying questions to be asked. Thereafter, we had to make individual lists of key words from our narratives and subsequently compared our lists to identify common key words that would serve as themes for further discussion. These common key words validated the identification of the following two themes: power and divide; shared goals and mutual benefit. We agreed to record our discussion and later transcribed it verbatim. 


\section{Presentation of Data}

Table 1 outlines our drawings as well as provide extracts from our narratives.

Table 1

Drawings and Narrative Extracts

\begin{tabular}{|c|c|c|}
\hline Number & Drawing & Extract from narrative \\
\hline 1 & 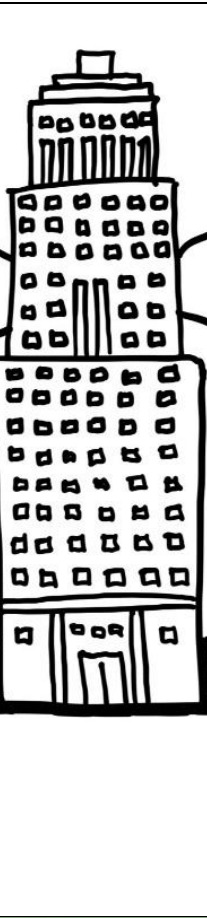 & $\begin{array}{l}\text { The Goliaths from the university come } \\
\text { with all the resources. People with } \\
\text { academic titles are recognised and } \\
\text { respected within the university as well as } \\
\text { the community spaces. The university is } \\
\text { an Ivory Tower far removed from its } \\
\text { community. Community engagement is } \\
\text { characterised by a power imbalance and } \\
\text { unequal distribution of resources. } \\
\text { Communities need to take huge steps } \\
\text { and go out of their way to collaborate } \\
\text { and bring their knowledge to the } \\
\text { partnerships, yet they are still not } \\
\text { recognised nor accepted by the } \\
\text { university as an equal partner. The main } \\
\text { question that comes to mind is: } \\
\text { "Research for who?" }\end{array}$ \\
\hline 2 & & $\begin{array}{l}\text { The university is perceived as the creator } \\
\text { of new knowledge, which comes with } \\
\text { ideas and does research on the } \\
\text { community. The drawing shows this } \\
\text { wide bridge which indicates the } \\
\text { connection between the university and } \\
\text { the community without being mindful of } \\
\text { the big divide and the challenges that } \\
\text { this divide causes between the university } \\
\text { and the community. The university flies } \\
\text { or drives into a community to } \\
\text { extrapolate data. However, it does not } \\
\text { create opportunities for communities to } \\
\text { solve real problems in their } \\
\text { communities. The community feels } \\
\text { exploited because once the university } \\
\text { achieves its research goals, the } \\
\text { community is left to fend for itself, with } \\
\text { no sustainable change in the community. } \\
\text { Thus, l am left to ask: "Research for } \\
\text { what?" }\end{array}$ \\
\hline
\end{tabular}




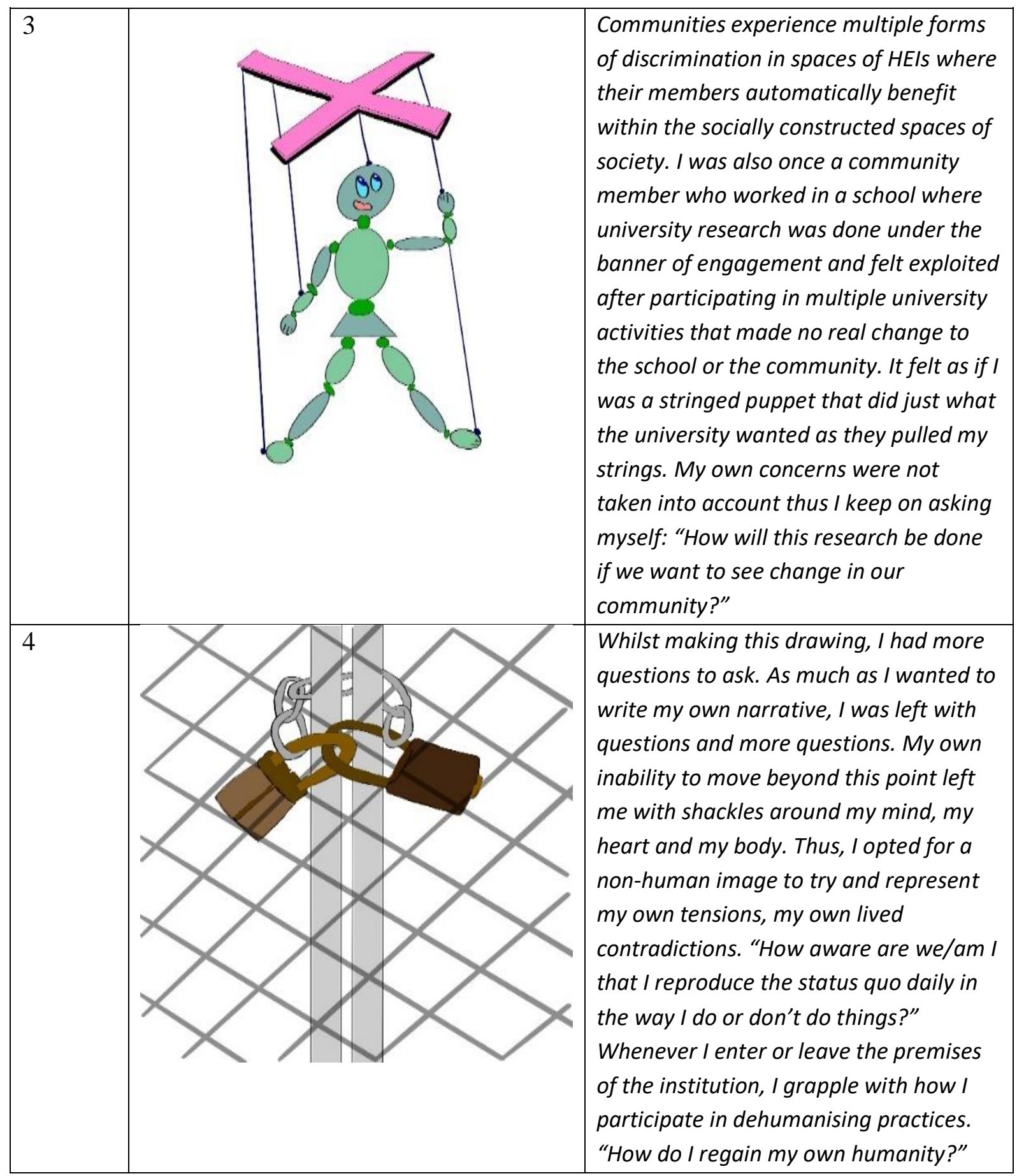

\section{Discussion of Findings}

We now proceed to an explication of our findings. An exposition of the themes identified in the methodology section is provided, with an explanation of our perceptions regarding how we experience university-community partnerships.

\section{Power and Divide}

From the data analysis, common key words that informed the theme of power and divide include imbalance of power and unequal resource distribution. We referred to the university as a "Goliath" or an "ivory tower" rich in resources such as skills and capacity to access, create, as well as apply knowledge. Although the community might have skills, they do not have the resources to use the skills 
to create knowledge. This reinforces the idea that community partners feel shackled by their circumstances and that they will not be able to make an equal contribution to the engagement partnership. This imbalance of power and unequal distribution of resources causes division and tension in engagement projects where the community is made to feel as if it has nothing to offer. Members are taken from their community context to well-resourced university campuses that are far removed from their lived realities and the challenges they experience daily. So how do we, as the university, start to question the structural inequalities and injustices that operate in university-community partnerships? How do we encourage the community to question the collective lie that continues to convince them to buy into the interests of the privileged and powerful without making a change to their own realities and challenges?

We experienced the above challenges as teachers in community schools and this history of how engagement was managed from the perspective of the institution makes it extremely difficult to forge engagement partnerships. Conscientisation is a dialectical process that demands researchers to respect their relationship with community members and the knowledge they own, as well as to acknowledge the lived realities of these communities (Freire, 1994). What is required is for university researchers to step down from the comfortable positions of power that institutions place them in and become co-learners with communities while upholding the required ethical protocols, adhering to respect, and doing no harm (Wood, 2016). They need to recognise that they are part of a structure that perpetuates the dominance of power and divide that leads to dehumanisation

We confirmed that the HEl system is characterised by bureaucratic structures that hamper the establishment of collaborative partnerships. This structure assumes that the task of engaging with communities has been delegated to universities and that their role is to "deliver" this engagement outcome. Ultimately, then, this leaves little room for the knowledge and lived experience of the communities to be acknowledged. Thus, this study postulates that because researchers are expected to produce knowledge they consciously or unconsciously reinforce the unequal power relations in engagement projects to achieve their research goals. These findings are substantiated by De Sousa Santos (2014) who suggested that real changes in HEls will only take place when the relationships of power begin to change, that is, when the concerns of the community are taken into account and the focus of HEls reflects the values of all. This will only happen when universities remove the locks from their gates, open themselves to alternative spaces of learning, and acknowledge the contribution that communities can make to knowledge construction.

\section{Shared Goals and Mutual Benefit}

We alluded to universities inviting communities to participate in engagement projects with preconstructed objectives and a research plan. This plan is usually one-dimensional and focuses on reaching the funders' objectives. So, when does the university put the sacred contract aside and ask the questions: "If this is meant to be a partnership, where is my partner (the community) in this plan?" "How are their (community) goals articulated in the research plans?" "How do we ensure that our research plans meet our shared goals and are mutually beneficial for both parties?"

Freire (1998) was of the opinion that the university agenda regarding community engagement will not change spontaneously. There is a need to create a learning context that questions and assists communities in how to make connections between their lived experience and the structures of society so that they can voice their goals and expectations in the engagement partnership (Ledwith, 2011). This facilitates problem posing in community engagement. We propose that these partnerships be democratic spaces in which partners can engage in critical dialogue to align their goals and objectives for mutual benefit. This will provide a common lens for the university and the community through 
which the world can be viewed. It will also serve as the foundation for co-designing solutions for real societal problems (Bhagwan, 2017).

Ledwith (2011) reminded us that our first priority in an engagement project is to get to know the community and its needs, and how these relate to the needs of the university and society at large. Critical pedagogy supports the above and compels us to listen actively to people's goals, expectations, ambitions, and dreams and to determine how it links to our own goals and expectations (Sathorar, 2018). This can only be achieved through dialogue amongst partners and it will, in turn, enhance the humanisation in the partnership. This will address community scepticism regarding engagement projects. As the data showed, they believe that the university comes to engagement projects with preconceived objectives. Thus, it is important to answer the following questions: "How does the university generate a sense of belonging and a sense of collaborative ownership for the community in the engagement project?" "How can the university create a space in the engagement project that will enable co-learning and co-creating of knowledge so that the community members do not feel as if they are puppets on a string-adhering to every command of the university at the cost of their own needs?"

The above discussion highlights the fact that there is a need for a renewed look at how universities engage with communities with a specific focus on ethical engagement practices (Wood, 2016). This does not just refer to doing no harm but also to ensuring that community members are treated as equal partners and that the community would be left with a sustainable benefit that will address real needs at the end of the engagement project. Below, we propose a critical engagement process that could enhance the way university academics engage with communities in engagement projects.

\section{The Way Forward: A Critical Approach to Enhance Community Engagement}

Freire (1994) posited that if universities want to fulfil the role of change agent through community engagement, they should be willing to share their authority with the community in community engagement projects, and they must encourage community participation through dialoguing and problem posing. It is imperative for universities to recognise the knowledge and experiences that the community bring to the engagement partnership, and to draw on these lived experiences when addressing societal problems in the local context (Wood, 2016). In this paper, we advocate for the application of a critical approach in university-community engagement projects. We propose the use of a critical engagement process as illustrated in Figure 1 to enhance the relationship between the university and the community and also to increase the mutuality of the outcomes of a project. 


\section{Figure 1}

\section{Critical Engagement Process}

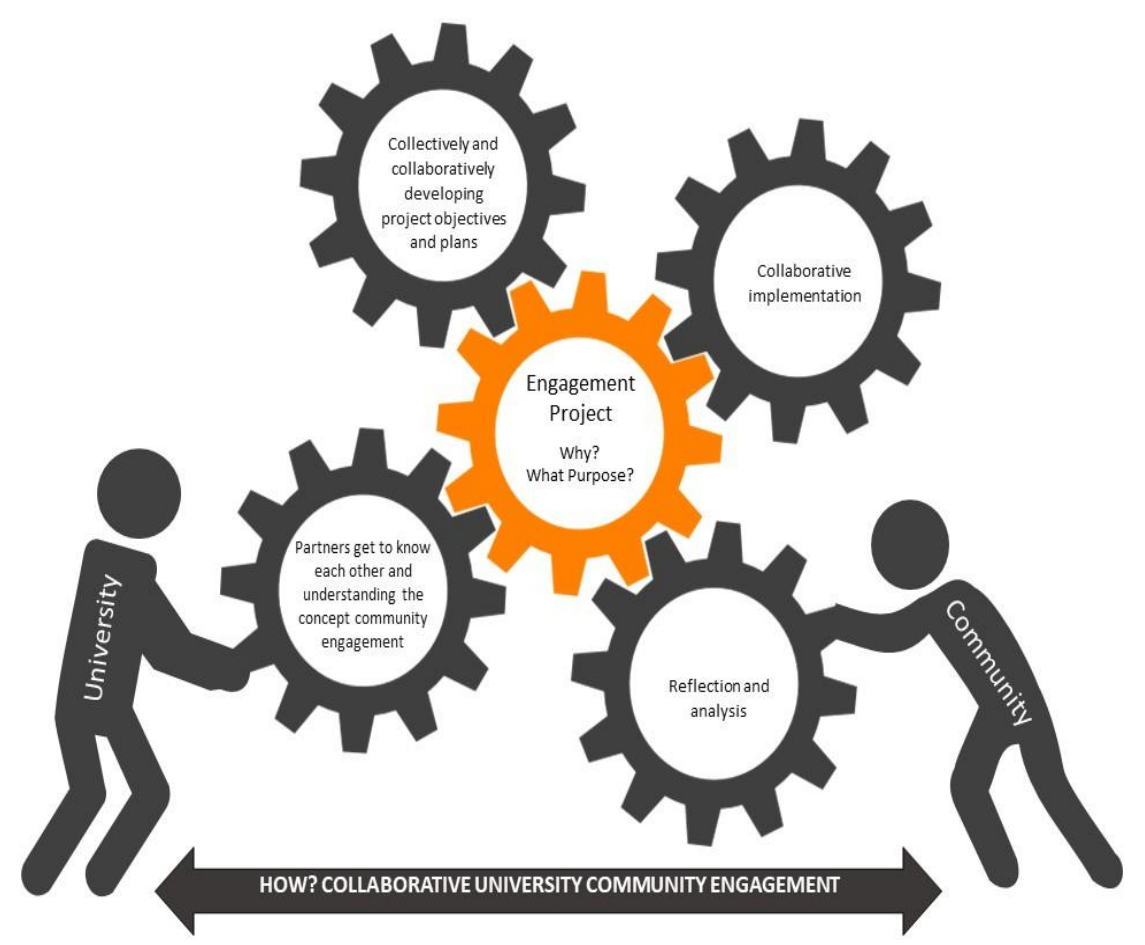

Our findings suggest that before researchers embark on engagement projects, they must ask themselves why they want to do the engagement activity. Similarly, they have to establish why communities might be interested in such a partnership. This forms the core of what drives any engagement process as can be seen in Figure 1 above. Universities, in collaboration with communities, should identify common issues of concern and develop overarching goals (what) that will bring about mutual benefit (Shannon \& Wang, 2010). Thus, the purpose of the engagement needs to be negotiated and it must be mutually beneficial. This will also ensure that universities engage in ethical researchbecause it will ensure that the community voice is taken into account and that the project results in a sustainable benefit for the community. If the community knows what the project is about and how they will benefit from it, it will reduce their scepticism and enhance their participation.

Researchers have emphasised the importance of how university-community engagement is done (Cooper \& Orrell, 2016; Strier, 2010). In the critical engagement process illustrated in Figure 1, we also focus on how engagement should take place and identify four critical interactions that will enhance how universities engage with communities. It is not envisaged that these critical interactions should take place in a linear or set manner; they can happen interchangeably. Furthermore, they are intrinsically and dependently linked to each other, and the process will not be complete if one of the interactions is dispelled. The university and the community are represented in the illustration of the process as people-highlighting the humanisation of the process and that both parties need to actively engage in the process for it to be mutually beneficial.

Moving in a clockwise direction from the bottom left of the illustration, the first interaction proposed is for university and community members to get to know each other and to understand the processes that will be followed in the project. True dialogue is required, and it needs to take place under the following conditions to enhance the humanisation of the project: profound love for the world and human beings, humility towards each other and the world, faith in humanity and in its power to create and re-create, and mutual trust between dialoguers (Freire, 1970). 
In the next interaction, the focus is on the university and community collectively establishing project plans. Understanding community needs, discussing, co-designing, and developing an implementable solution will no longer make the community feel as if the university is imposing a solution on them (Bhagwan, 2017). Co-designing solutions will allow for the community to develop a voice. The collective collaboration will contribute to conscientisation and allow for the university and its community partners "to learn to perceive social, political and economic contradictions and to take action against the oppressive elements of reality" (Freire, 1970, p. 17). Applying a critical approach requires tapping into all voices and recognising all knowledge that is available to contribute to a plan. Thus, a problemposing strategy is required where the university and the community analyse and interrogate their own knowledge and experiences in relation to those of others to reveal larger public issues and processes of domination and liberation (Darder, 2017).

The third critical interaction refers to the collective and collaborative implementation of project plans. Here, the focus of mutuality and reciprocity will involve the university gathering data while, at the same time, community leadership needs to be developed and skills provided to address the needs of the community. This will ensure that communities do not feel as if they have been exploited in a process where the focus was just on the research outcomes for the university (Cooper \& Orrell, 2016). The skills development will contribute to the sustainability of the project.

The final critical interaction proposes a process of reflection and analysis that will allow the university and community to critically look at what has happened in the project and to identify where they need to change what they are doing. This interaction, like all the others, is dependent on true dialogue between the university and the community, and this will only be possible if a trust relationship has been developed.

This model embraces the participatory action research (PAR) strategy but differs from other PAR models in that it focuses on engaging in an ethical manner by applying the critical pedagogy principles of humanisation, true dialogue, conscientisation, and problem posing. In order for university researchers to embrace the application of a critical approach to community engagement, they need to be exposed to the critical pedagogy principles. These principles need to be explained and practically demonstrated to researchers and we propose that, before they participate in community engagement projects, they participate in a short learning programme or workshop during which they are introduced and allowed to practically experience the critical approach process. During this programme, researchers and their community partners can respond to why do the engagement project, what is the purpose of the project, and how will they engage in the project.

\section{Conclusion}

In this paper, we reflect on the development of meaningful university-community partnerships capable of bringing about mutual benefits and reciprocity by the equal and lived inclusion of excluded communities. The building of a lasting partnership demands balancing power relations between partners, as well as the coordination of contrasting perceptions. The scholarship of community engagement requires a critical academy that will prioritise community development instead of focusing on increasing institutional research outputs. This requires researchers to link their research to real community problems that will not just bring about research outputs but also contribute to sustainable solutions that will bring about social transformation.

When the notions of mutuality and reciprocity are forefronted in university-community partnerships, authentic engagements emerge that support the development of collaborative communities that work together to create new knowledge. In conclusion, university-community engagement should be a 
priority at universities and not seen as an add-on to teaching and research because it is a philosophical belief that can help evolve, shape, and progress higher education.

\section{References}

Bhagwan, R. (2017). Towards a conceptual understanding of community engagement in higher education in South Africa. Perspectives in Education, 35(1), 171-185. http://dx.doi.org/10.18820/2519593X/pie.v35i1.13

Boyer, E. (1990). Scholarship reconsidered: Priorities of the professoriate. The Carnegie Foundation for the Advancement of Teaching. https://www.umces.edu/sites/default/files/al/pdfs/BoyerScholarshipReconsidered.pdf

Brookfield, S. (2017). Becoming a critically reflective teacher (2nd ed.). Jossey-Bass.

Bruce, D., \& Chiu, M. (2015). Exploring the transition into academia through collaborative self-study. Studying Teacher Education, 66(3), 272-287. https://doi.org/10.1080/17425964.2011.591173

Centre for Higher Education Transformation. (2003). Policy/change dialogue report. Terms of engagement: Renewing the role of the university as an urban institution.

Cooper, L., \& Orrell, J. (2016). University community engagement: Towards a partnership based on deliberate reciprocity. In F. Trede \& C. McEwen (Eds.), Education the deliberate professional: Preparing for future practices (pp.107-138). Springer.

Cooper, L., Orrell, J., \& Bowden, M. (2010). Work integrated learning: A guide to effective practice. Taylor \& Francis.

Darder, A. (2017). Reinventing Paulo Freire: A pedagogy of love. Routledge.

Department of Education. (1997). Education White Paper 3: A programme for higher education transformation. https://www.gov.za/sites/default/files/gcis document/201409/18207gen11960.pdf

De Sousa Santos, B. (2014). Epistemologies of the South: Justice against epistemicide. Paradigm.

Edmondson, J., \& Zimpher, N. L. (2014). Striving together. SUNY Press.

Elbow, P. (1973). Writing without teachers. Oxford University Press.

Elbow, P. (1998). Writing with power (2nd ed.). Oxford University Press.

Fataar, A., \& Subreenduth, S. (2016). The search for ecologies of knowledge in the encounter with African epistemicide in South African education. South African Journal of Higher Education, 29(1), 106-121. https://doi.org/10.20853/29-2-468

Flick, U. (2014). An introduction to qualitative research (5th ed.). SAGE.

Freire, P. (1970). Pedagogy of the oppressed. Continuum.

Freire, P. (1994). Education for critical consciousness. Continuum.

Freire, P. (1998). Pedagogy of the heart. Continuum.

Gilbertson, S. (2013). Improvisation and meaning. International Journal of Qualitative Studies on Health and Well-Being, 8(1). https://doi.org/10.3402/qhw.v8i0.20604

Giroux, H. (2006). Challenging neoliberalism's new world order: The promise of critical pedagogy. Palgrave Macmillan.

Hammersley, M. (2013). What is qualitative research? Bloomsbury. 
Holland, P., \& Ramaley, J. (2008, July 1-4). Creating a supportive environment for communityuniversity engagement: Conceptual frameworks. In Engaging Communities, proceedings of the 31st HERDSA annual conference, Rotorua, New Zealand (pp. 33-47). https://www.herdsa.org.au/publications/conference-proceedings/research-and-developmenthigher-education-place-learning-and-62

Jadhav, J. U., \& Suhalka, V. (2016). University community engagement: Insights from field work practices. Indian Journal of Sustainable Development, 2(1), 22-28. https://papers.ssrn.com/sol3/papers.cfm?abstract id=2793826

Kruss, G. (2012). Reconceptualising engagement: A conceptual framework for analysing university interaction with external social partners. South African Review of Sociology, 43(2), 5-26. https://doi.org/10.1080/21528586.2012.694240

Ledwith, M. (2011). Community development: A critical approach. Policy Press.

Leedy, P. D., \& Ormrod, J. E. (2018). Practical research: Planning and design (12th ed.). Pearson.

Maxwell. J. (2012). A realist approach for qualitative research. SAGE.

McNair, T. B., \& Ramaley, J. A. (2018). Equity and inclusion: Expanding the urban

ecosystem. Metropolitan Universities, 29(1), 3-10. https://doi.org/10.18060/22167

Mtawa, N. N., Fongwa, S. N., \& Wangenge-Ouma, G. (2016). The scholarship of university-

community engagement: Interrogating Boyer's model. International Journal of Educational Development, 49, 126-133. https://doi.org/10.1016/i.ijedudev.2016.01.007

Muthwa. S. (2018). Taking Nelson Mandela University boldly into the future in service of society. Nelson Mandela University. https://www.mandela.ac.za/wwwnew/media/Store/documents/Leadership/V2030/Mandela-Uni-VC-s-Inaugural-AddressSibongile-Muthwa-April-2018.pdf

Nouri, A., \& Sajjadi, S. M. (2014). Emancipatory pedagogy in practice: Aims, principles and curriculum orientation. International Journal of Critical Pedagogy, 5(2), 76-87. http://libjournal.uncg.edu/ijcp/article/view/228/671

Rose, G. (2016). Research ethics and visual materials: Consent. In R. Rojek (Ed.), Visual methodologies (4th ed., pp. 362-366). SAGE.

Sathorar, H. (2018). Exploring lecturer preparedness on applying a critical approach to curriculum implementation: A case study [Doctoral dissertation, Nelson Mandela University]. SEALS Digital Commons.

http://vital.seals.ac.za:8080/vital/access/manager/Repository/vital:31828?site name=GlobalVie $\underline{w}$

Shannon, J., \& Wang, T. R. (2010). A model for university-community engagement: Continuing educations' role as convener. Journal of Continuing Higher Education, 58, 108-112. https://doi.org/10.1080/07377361003661499

Shor, I. (1992). Empowering education: Critical teaching for social change. University of Chicago Press.

Shudak, N. J. (2014). The re-emergence of critical pedagogy: A three-dimensional framework for teacher education in the age of teacher effectiveness. Creative Education, 5(11), 989-999. https://doi.org/10.4236/ce.2014.511113

Smith, J., Pelco, L. E., \& Rooke, A. (2017) The emerging role of universities in collective impact initiatives for community benefit. Metropolitan Universities, 28(4), 9-21. https://doi.org/10.18060/21743

Stenhouse, L. (1975). An introduction to curriculum research and development. Heineman. 
Strier, R. (2010). The construction of university community partnerships: Entangled perspectives.

Higher Education. Springer Science \& Business Media.

http://reforma.fen.uchile.cl/Papers/The\%20construction\%20of\%20university-

community\%20partnerships\%20-\%20Strier.pdf

Vanassche, E., \& Kelchtermans, G. (2016). Facilitating self-study of teacher education practices: Toward a pedagogy of teacher educator professional development. Professional Development in Education, 42(1), 100-122. https://doi.org/10.1080/19415257.2014.986813

Wood, L. (2016). Community development in higher education: How do academics ensure their community-based research makes a difference? Community Development Journal, 52(4), 685-701. http://doi.org/10.1093/cdj/bsv068

Zuber-Skerritt, O., Wood, L., \& Kearney, B. (2020). The transformative potential of action learning in community-based research for social action. Action Learning: Research and Practice. 17(1), 34-47. https://doi.org/10.1080/14767333.2020.1712840 